\title{
The autoantibody-mediated encephalitides: from clinical observations to molecular pathogenesis
}

\author{
Sudarshini Ramanathan ${ }^{1,2,3,4} \cdot$ Adam Al-Diwani $^{1,2,5} \cdot$ Patrick Waters $^{1,2} \cdot$ Sarosh R. Irani ${ }^{1,2,6}$ (C)
}

Received: 28 July 2019 / Revised: 15 October 2019 / Accepted: 17 October 2019 / Published online: 26 October 2019

(c) The Author(s) 2019

\begin{abstract}
The autoimmune encephalitis (AE) syndromes have been characterised by the detection of autoantibodies in serum and/or cerebrospinal fluid which target the extracellular domains of specific neuroglial antigens. The clinical syndromes have phenotypes which are often highly characteristic of their associated antigen-specific autoantibody. For example, the constellation of psychiatric features and the multi-faceted movement disorder observed in patients with NMDAR antibodies are highly distinctive, as are the faciobrachial dystonic seizures observed in close association with LGI1 antibodies. These typically tight correlations may be conferred by the presence of autoantibodies which can directly access and modulate their antigens in vivo. AE remains an under-recognised clinical syndrome but one where early and accurate detection is critical as prompt initiation of immunotherapy is closely associated with improved outcomes. In this review of a rapidly emerging field, we outline molecular observations with translational value. We focus on contemporary methodologies of autoantibody detection, the evolution and distinctive nature of the clinical phenotypes, generalisable therapeutic paradigms, and finally discuss the likely mechanisms of autoimmunity in these patients which may inform future precision therapies.
\end{abstract}

Keywords Autoimmune encephalitis · NMDAR encephalitis · LGI1 encephalitis · Neuroimmunology · Autoantibodies · Seizures

\section{Introduction}

For over 5 decades, the clinical syndrome characterised by the subacute onset of amnesia, agitation, confusion, hallucinations, seizures and sleep disturbance, often accompanied

Sudarshini Ramanathan and Adam Al-Diwani contributed equally.

Sarosh R. Irani

sarosh.irani@ndcn.ox.ac.uk

1 Oxford Autoimmune Neurology Group, Nuffield Department of Clinical Neuroscience, John Radcliffe Hospital, Oxford, $\mathrm{UK}$

2 University of Oxford, Oxford, UK

3 Sydney Medical School, University of Sydney, Sydney, Australia

4 Kids Neuroscience Centre, Children's Hospital at Westmead, Sydney, Australia

5 Department of Psychiatry, Warneford Hospital, University of Oxford, Oxford, UK

6 Department of Neurology, Oxford University Hospitals NHS Foundation Trust, Oxford, UK by medial temporal lobe signal changes on imaging, has been referred to as limbic encephalitis (LE) [1-3]. Some patients with LE have defined autoantibodies which are not thought to be directly pathogenic, and target intracellular onconeural antigens including nuclear or cytoplasmic proteins (such as $\mathrm{Hu}, \mathrm{Ma}, \mathrm{Ri}$, and Yo) [2]. These patients often have underlying malignancies and these are likely dominantly T cell-mediated conditions [4-6].

By contrast, in recent years, a group of autoimmune encephalitis (AE) syndromes have been characterised by the detection of autoantibodies in serum and/or cerebrospinal fluid (CSF) which target the extracellular domains of specific neuroglial cell-surface antigens [2, 3, 7-10]. These autoantibodies can access their target antigens in vivo, and it is now widely accepted that their disruption of the target antigen results in the observed neurological sequelae $[6,7,11-14]$. Therefore, these antibodies have pathogenic potential and their early and accurate detection is critical for two main pragmatic clinical reasons. First, the incidence of autoantibody-mediated encephalitis is equivalent to that of infectious encephalitis [15]. In our clinical experience, it is likely to exceed the frequency of infectious causes, when the 
seronegative forms of AE are also taken into account. Second, while the clinical manifestations may range from mild to life threatening, the syndromes are typically responsive to immunotherapy [7], with early treatment being consistently identified as a factor in improved long-term outcomes [8, $16,17]$. Hence, this review will summarise features which should encourage early clinical recognition and outline current treatment strategies. In addition, we discuss autoantibody detection methods and describe contemporary insights into the neuroscience and cellular immunology which underlie these fascinating conditions.

\section{Relative merits of autoantibody detection methods}

All autoantibodies which mediate AE bind conformational antigenic epitopes. The tertiary structure of the target protein is thought to create distinctive three-dimensional domains to which autoantibodies preferentially bind. Conversely, loss of this structure reduces the likelihood of binding and subsequent detection of potentially pathogenic autoantibodies. This principle has underpinned the development of assays used in discovery phase research as well as those optimised for routine diagnostic testing (Fig. 1).

HEK293 cells provide a robust system for expressing proteins in their native conformational state on a mammalian surface membrane. As a result, they are a key reagent in the successful mammalian expression of the conformationally active extracellular domains of the known target antigens. Indeed, they are commonly employed in cell-based assays (CBAs), and have roles both in research to test for candidate targets, and in diagnostic testing to specifically identify a clinically suspected autoantibody. The patient serum or CSF can be applied to the transfected HEK cells either when they are live and intact ('live CBA') or after fixation and permeabilization ('fixed CBA'). Live CBAs avoid permeabilisation and fixation-induced disruption of autoantigens, so patient autoantibodies are only exposed to the most clinically relevant extracellular epitopes. In our experience, this testing approach contributes to higher sensitivity for detecting immunotherapy-responsive conditions [18-21]. However, the cells must be cyclically prepared and used within a narrow time window, limiting their availability to expert laboratories. By contrast, fixed CBAs expose potentially denatured and intracellular antigens, but can be easily disseminated to other labs and used after preparation for several months.

Live cultured rodent neurons or fixed brain slices provide substrates for 'neuron-based assays' or 'tissue-based assays', respectively. These preparations express the native epitopes from neurons, rather than those expressed by non-neuronal, albeit mammalian, cells such as HEK cells. Therefore, they may further improve the detection of autoantibodies

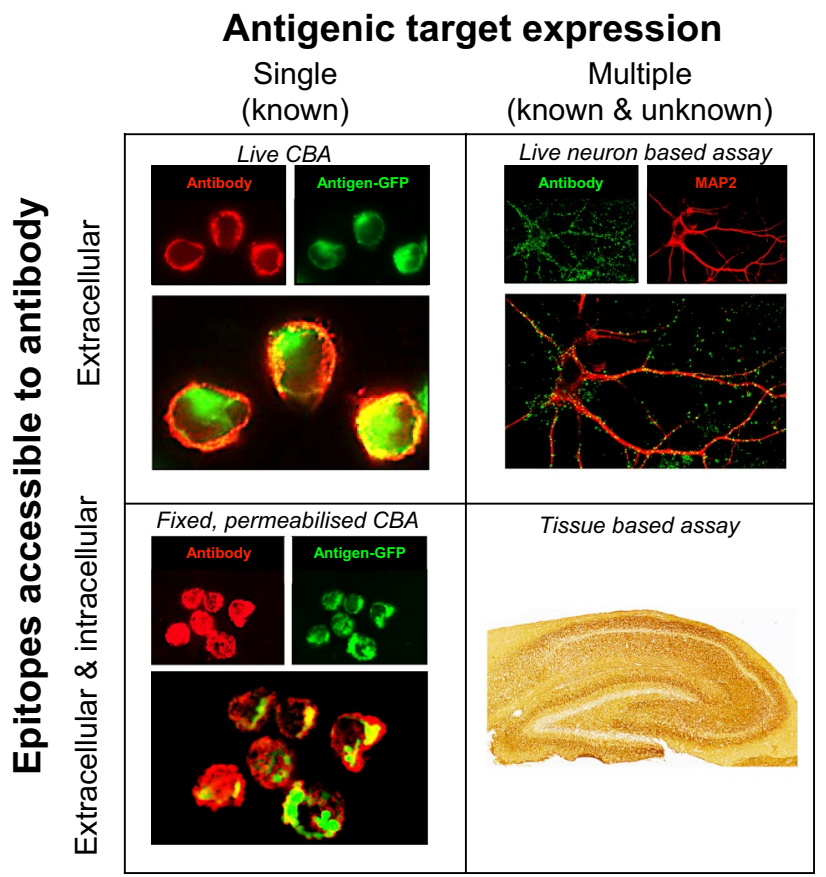

Fig. 1 Neuronal surface antibody detection methods. Prevailing methods used in research and diagnostic practice expose neuronal antigens to the test sample but differ in the properties of the antigen(s). Cell-based assays (CBA) aim to largely expose a single known antigen, by cell transfection. Conversely, neuron-based assays and tissue-based assays expose multiple natively expressed antigens which include those known to be targets of pathogenic antibodies, in addition to as-yet unknown antigens. Additionally, the assays vary on whether the antigen is fixed prior to incubation with the sample, and whether the cell membrane is intact. Live CBAs and live neuron-based assays neither fix the surface antigen nor permeabilise the membrane prior to exposure to the patient's sample. In contrast, in fixed permeabilised CBAs and tissue-based assays, target antigens are fixed and cell membrane integrity is lost. $C B A$ cell-based assay

with pathogenic potential. Theoretically, they can be used to screen for binding to any endogenous neuronal antigen, although fixed slices will of course detect antibodies which bind intracellular targets. Additionally, they may yield highly characteristic binding patterns and provide information about subcellular and whole brain localisation of autoantigens. These approaches depend on considerable technical expertise to optimise antigen availability, autoantibody detection, and image interpretation. Consequently, their main role remains in research laboratories for autoantibody discovery, or as an adjunct to confirm CBA-determined autoantibody specificities in more native tissue $[3,21]$.

\section{Use of serum versus CSF}

The relative value of serum versus CSF for testing provides an interesting set of challenges. Serum has both a high level of $\operatorname{IgG}$ (around $10 \mathrm{mg} / \mathrm{mL}$ ) and a huge diversity of 
antibody-binding specificities. Hence, serum testing is inherently challenging, compared to the approximately 500 -fold lower total IgG in CSF. However, as nearly all potentially pathogenic antibodies have a higher concentration in serum compared to CSF, likely reflecting their initial peripheral generation, serum findings have biological and diagnostic importance. Particularly in serum, high-sensitivity assays permit the detection of target-specific conformational antibodies that are of low affinity and/or at a low level [22, 23]. However, the detection of these lower affinity/level antibodies may increase the likelihood of detecting autoantibodies which lack direct clinical relevance with respect to the canonical AE syndrome in question. Yet, these findings appear to be biochemically robust in defining the presence of antigen-specific reactivities [20, 22, 23]: they do not appear to be false-positive results. Hence, we prefer the term clinically irrelevant as they do not currently appear directly translatable to the level of individual patients. In contrast, CSF provides a 'cleaner' sample for autoantibody determination and in many cases of $\mathrm{AE}$ there is a relative overproduction of the antigen-specific autoantibodies in the intrathecal compartment ('intrathecal synthesis'), as reflected in the high frequencies of antigen-specific $B$ cells in CSF [2, 24-26]. For some AE autoantibodies, this confers CSF with low background, and it can often be tested with minimal dilution to boost sensitivity without concern about loss of specificity. However, some AE autoantibodies-such as those against LGI1 - are preferentially detected in serum versus CSF in clear-cut clinical cases [27] (Michael, Ramberger, and Irani, unpublished observations). Therefore, overall, the literature and our experience suggest that paired serum-CSF testing in the context of a clear pre-test clinical probability forms the basis of a reliable diagnostic approach. This a priori clinical hypothesis remains the cornerstone of successful diagnostic testing and is, therefore, the focus of the next section.

\section{Clinical features of the neuronal surface autoantibody-mediated encephalitis syndromes}

$\mathrm{N}$-Methyl-D-aspartate receptor (NMDAR) and leucine-rich glioma-inactivated 1 (LGI1) antibodies define the most prevalently recognised AE syndromes, and will be the primary focus of this review (Table 1). In addition, over the last decade, numerous other CNS antigens have been identified as targets in less frequent, clinically varied forms of AE. These autoantibodies are directed against the $\gamma$-aminobutyric acid $\mathrm{A}$ and $\mathrm{B}$ receptors $\left(\mathrm{GABA}_{\mathrm{A} / \mathrm{B}}\right), \alpha$-amino-3-hydroxy5-methyl-4-isoxazolepropionic acid receptor (AMPAR), glycine receptor (GlyR), dipeptidyl-peptidase-like protein-6 (DPPX), dopamine 2 receptor (D2R), metabotropic glutamate receptor 5 (mGluR5), neurexin-3 $\alpha$, and IgLON5. The demographics, clinical presentations, paraclinical investigations, and the therapeutic responses of these individual syndromes are summarised in Table 2. Much of this clinical information is based on retrospective diagnoses and relatively small cohorts. Nevertheless, almost all studies still point towards a consistent paradigm of an autoantibodymedicated encephalitis occurring over an acute or subacute duration, often with associated impaired cognition, neuropsychiatric manifestations, seizures, movement disorders, and sleep dysfunction, with or without a tumour association; and a high likelihood of response to immunotherapy.

In clinical practice, it is well recognised that a proportion of patients present with similar features and do not have detectable autoantibodies. These 'phenocopies' are typically diagnosed as having a seronegative AE, and it is presumed that they have as-yet unrecognised neuronal surface autoantibodies [25, 28, 29]. This concept has been recently highlighted by a study describing 38 patients with immunotherapy-responsive brainstem-cerebellar presentations and opsoclonus, plus ovarian teratomas, yet absent NMDAR antibodies [30]. In such patients, it remains essential to make a clinical diagnosis [28], exclude alternate aetiologies, and manage these patients with immunotherapeutic treatment algorithms which are based on those with proven neuronal surface autoantibody-associated syndromes. Indeed, recent consensus criteria have been developed with 'possible', 'probable', and 'definite' classifications of the disease to promote instigation of immune treatments on the balance of clinical probabilities, while investigations are arranged [28].

\section{Signature features of NMDAR-antibody encephalitis}

NMDAR-antibody encephalitis is one of the most common autoimmune encephalopathies [15, 31]. While it can affect all ages and sexes, it most frequently presents in young females. It is associated with ovarian teratomas in $20-40 \%$ of cases, but has a greater female preponderance even when this is taken into account. This demographic pattern is in direct contrast to the other common AE syndrome, associated with LGI1 antibodies (Fig. 2A and Table 1). In addition to this separation, patients with LGI1 antibodies are rarely of African or Caribbean descent, whereas patients with NMDAR antibodies are often within this ethnicity $[8,16]$.

The clinical syndrome and the associated NR1 subunit $\mathrm{IgG}$ antibodies were characterised as recently as the mid-2000s [32-36]. Yet, while newly described, it is most likely not a de novo clinical disease entity. The characteristic progressive pattern of abrupt-onset bizarre behaviour, typically followed a few days later by abnormal movements, seizures, dysautonomia, and disruption of consciousness, is 


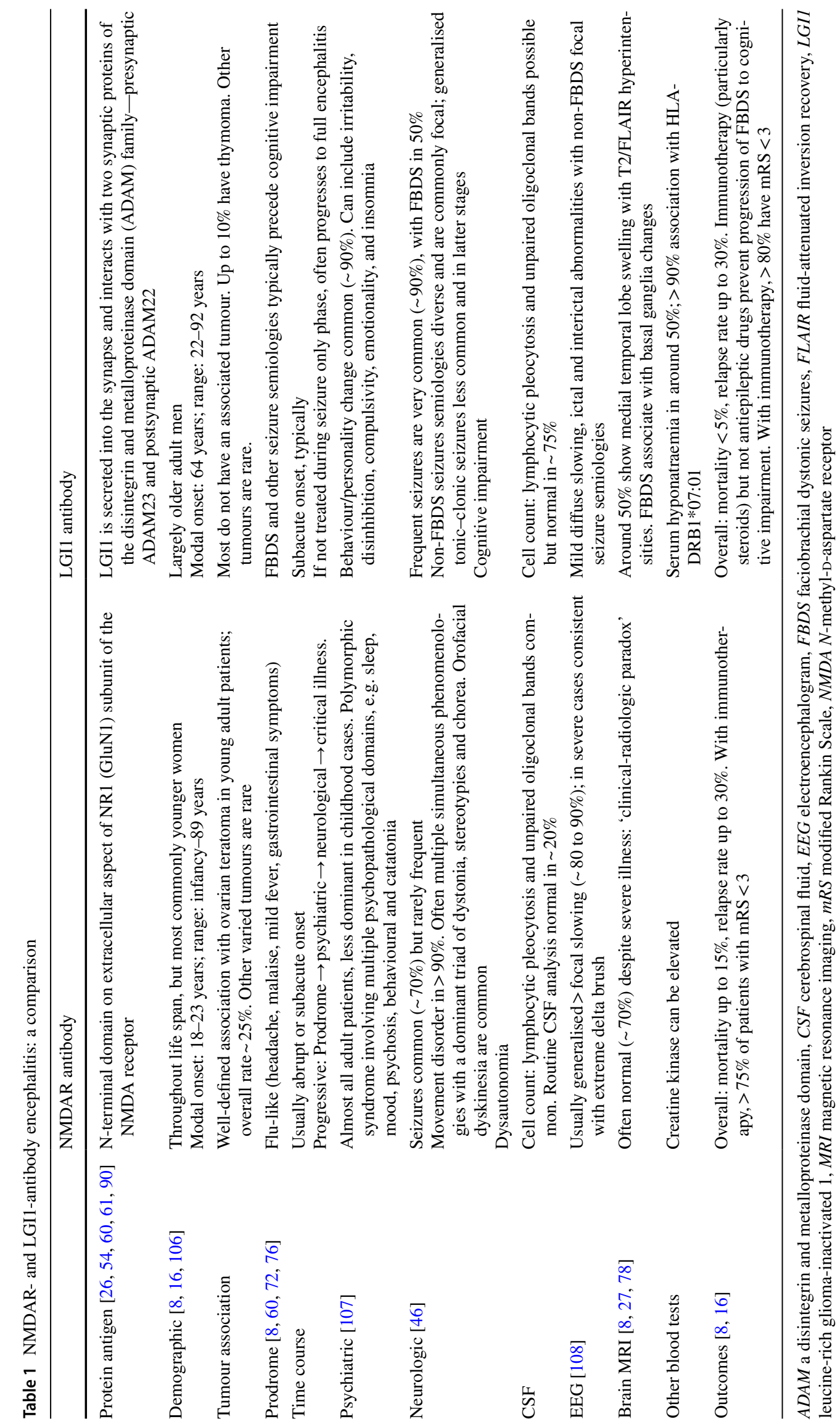




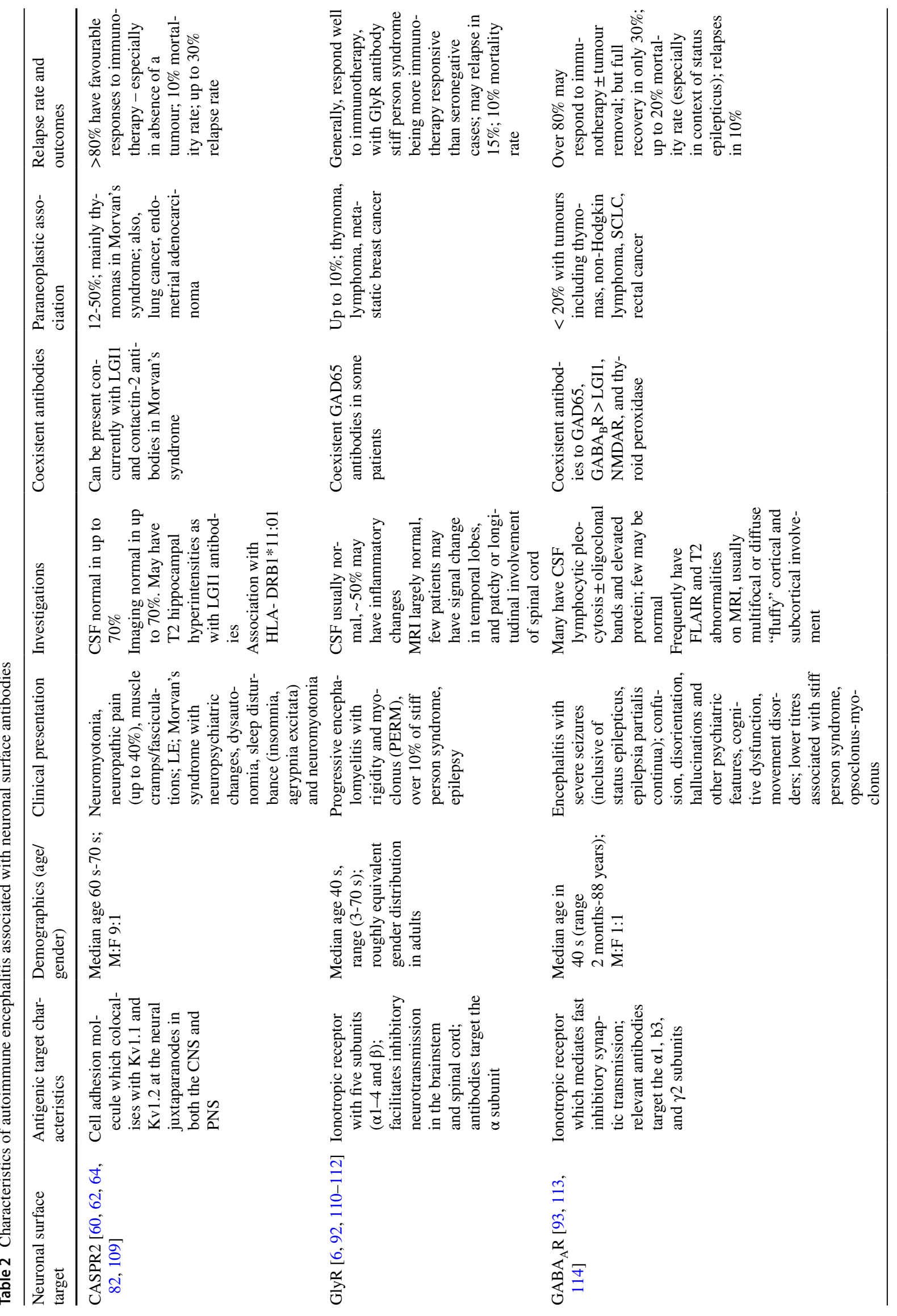




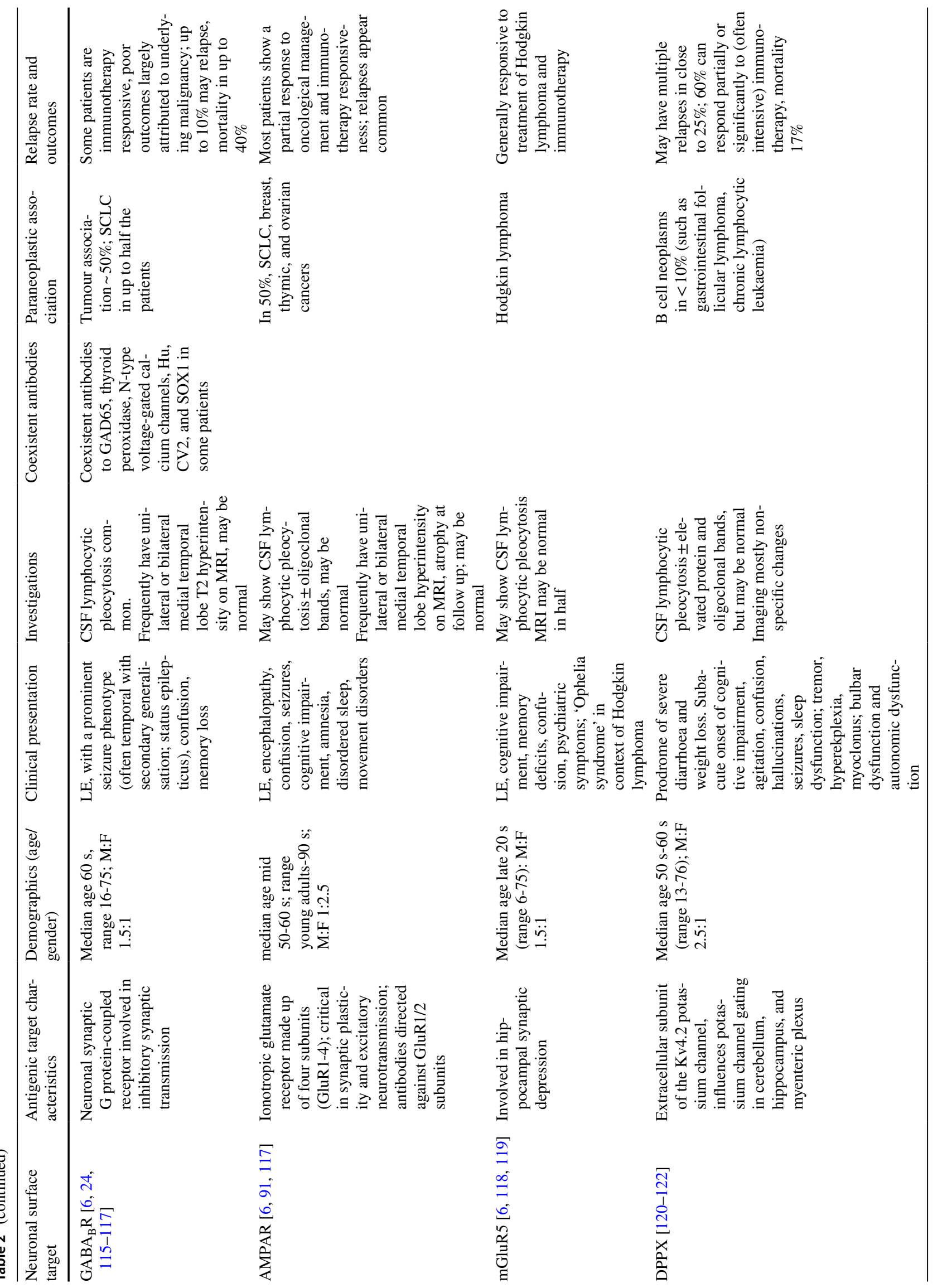




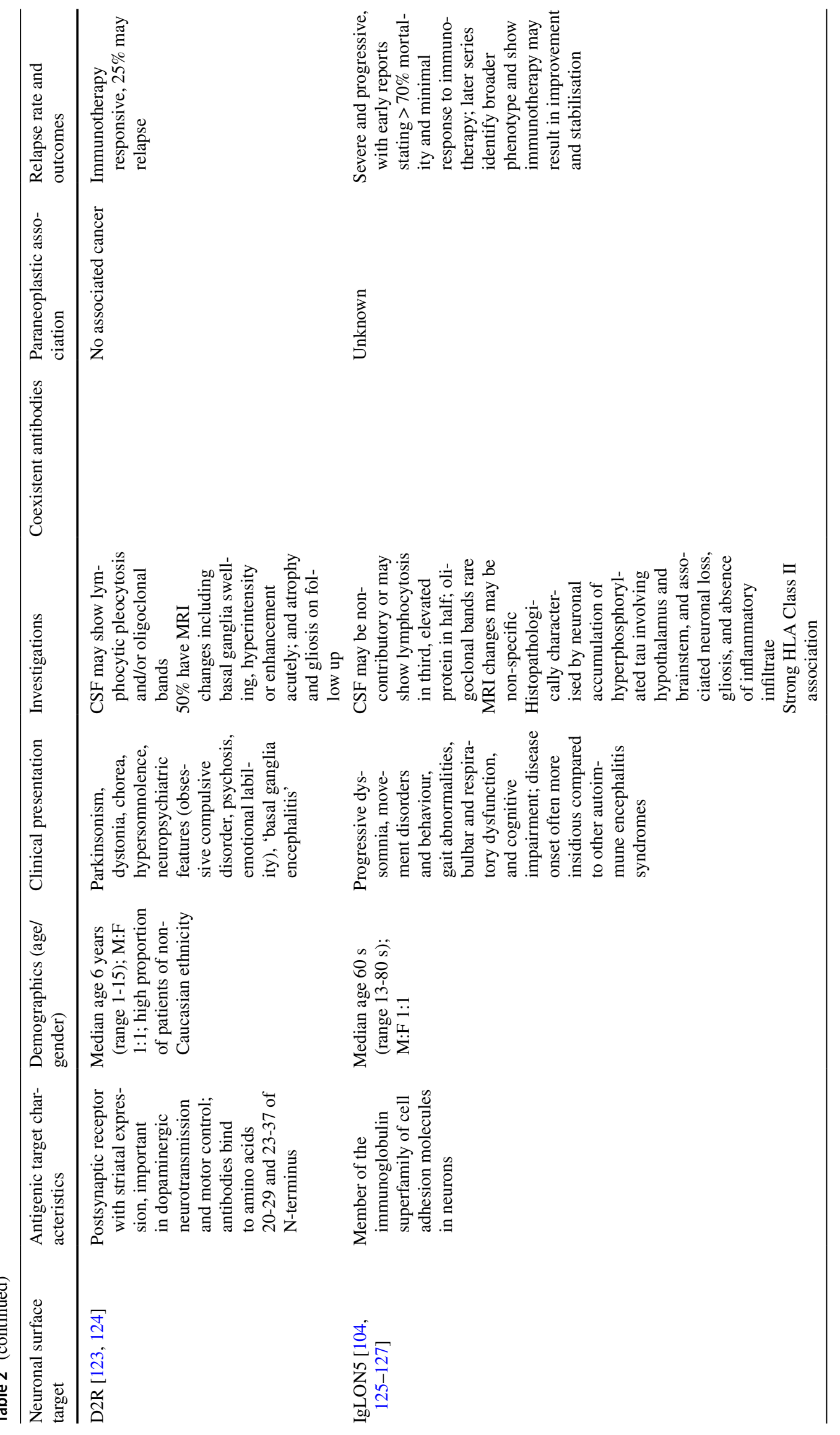




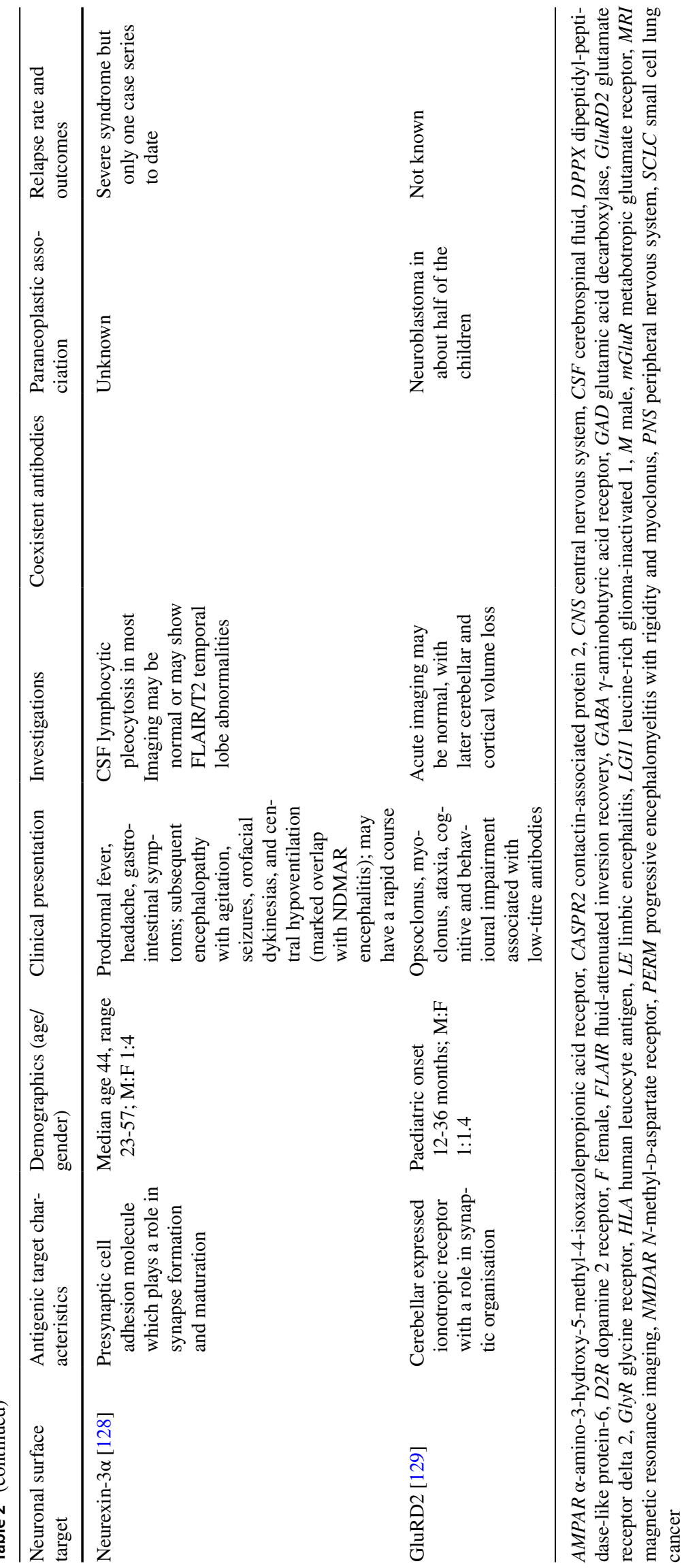


A

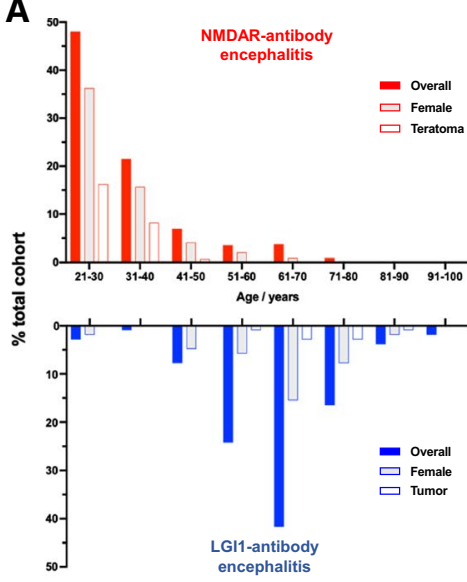

C

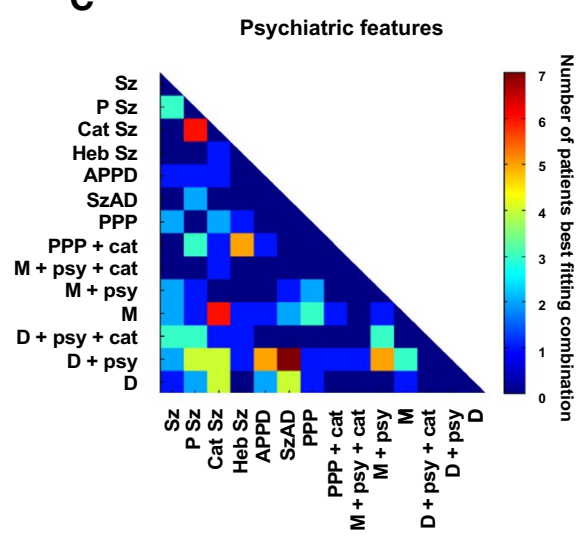

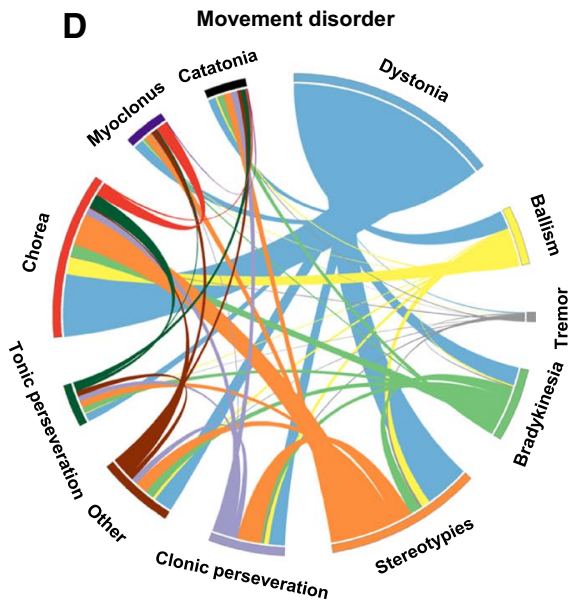

Fig. 2 Characteristic aspects of NMDAR-antibody encephalitis. a Comparison of age, sex, and tumour association in adult patients with NMDAR (red) versus LGI1-antibody encephalitis (blue). b The ovarian teratomas associated with NMDAR-Ab-E can contain germinal centre-like structures. Here, T (CD3) and B (CD20) cell lineages are present, along with classical plasma cells (CD138), markers of $\mathrm{T}$ and B cell subsets (CD27 and CD38), plus the target antigen, the NR1 subunit of the NMDA Receptor. Reproduced with permission from [97]. c The presentation of NMDAR-Ab-E typically includes psychiatric features and movement disorders. These are both characterised by high levels of complexity, blending phenotypes which are usu- ally discrete in individual patients. Here, a sub-group of individually reported patients $(n=115)$ with $\geq 6$ psychiatric features are compared with 14 primary psychiatric disorders using constrained combination analysis. The heat map shows the pairs which best describe the data from [47]. d The movement disorder similarly combines multiple phenomenologies including stereotypies, dystonia and chorea. Modified with permission from [46]. APPD acute polymorphic psychotic disorder, Cat $\mathrm{Sz}$ catatonic schizophrenia, D depression, Heb $S z$ hebephrenic schizophrenia, $M$ mania, $P P P$ postpartum psychosis, $P S z$ paranoid schizophrenia, $S z$ schizophrenia, $S z A D$ schizoaffective disorder, + cat with catatonia, $+p s y$ with psychotic features reminiscent of multiple syndromes previously designated as malignant catatonia, dyskinetic encephalitis lethargica, acute juvenile female non-herpetic encephalitis, and even preternatural explanations such as demonic possession [37-39]. Despite greatly increased awareness over the past decade, this symptomatic overlap with medical and non-medical concepts beyond the scope of neurology continues to risk delay in diagnosis and instigation of disease-modifying therapies.

Since the initial descriptions of NMDAR-antibody encephalitis, our understanding of the illness has been refined. This has included the identification of cases in both sexes and most commonly, without tumours; the recognition of herpes simplex encephalitis as a trigger; and the role of lymphocyte-targeted second-line immunotherapies as effective in relapse prevention [16, 40-42]. Our group and others have systematically studied the two most prominent and common clinical manifestations of this disease: the psychiatric features and movement disorders. The primary aim of such studies is not only to improve both positive identification of patients with an immunotherapy-responsive syndrome, but also to limit overconsideration of the diagnosis in presentations where the autoantibodies are not clinically relevant. In summary, the main finding has been that NMDAR-antibody encephalitis is associated with highly complex phenotypes that sample aspects from multiple sub-syndromal domains [43]. For example, the movement disorder shows almost all recognised movement disorder phenomenologies, albeit with markedly differing frequencies [44-46]. Most commonly, the movement disorder is best described by a combination of dystonia, stereotypy, and chorea with little tremor (Fig. 2b) [46]; these phenomenologies are very rarely seen together in other neurological conditions making this combination highly distinctive for NMDAR-antibody encephalitis. In an analogous manner, the mental state shows a pattern that fits poorly with primary psychiatric features and a study highlighting the psychopathological features across 464 individual patients with 
NMDAR-antibody encephalitis described a highly mixed mood-psychotic disorder with prominent disorganisation that only a combination of mixed primary disorders could adequately model [47]. Strikingly, an individual patient can manifest up to twenty different psychiatric features. These patterns, while complex over the time course of the disease, show strong levels of coherence indicative of consistency between patients (Fig. 2b). Recent observations also suggest that other distinctive findings in the acute phase include wandering, behavioural regression, and an abnormal sense of strength [130]. Taken together, we suggest that this stereotyped complexity can help clinicians in emergency medicine, psychiatry, and neurology develop an index of suspicion at the earliest clinical phases and, therefore, arrange for paired serum-CSF antibody testing, and prompt consideration of empirical immunotherapies [48-50]. This is critical as widespread testing of serum without refining the clinical syndrome can lead to conflation of other neurological and psychiatric disorders with NMDAR-antibody encephalitis and downstream errors of omission (lack of management of the actual diagnosis) and commission (administration of immunotherapy and exposure to side effects without a clear indication) [23, 51].

Application of contemporary molecular and systems neuroscience continues to expand our understanding of how autoantibody-receptor interactions can provoke such a clinically distinctive disease. Indeed, it is of relevance that ketamine closely mimics several aspects of the psychopathology and movement disorders associated with NMDARantibody encephalitis, suggesting that modification of the NMDAR alone may be sufficient to explain the clinical observations [10, 35]. Appreciating receptor-level modifications may assist in identifying optimal symptomatic therapies, as well as developing new approaches targeting the stabilisation of NMDAR-expressing synapses. For example, single-molecule microscopy techniques have demonstrated that loss of synaptic NMDAR localisation, via disruption of NMDAR-EphB2 interactions and postsynaptic density organisation, is a key pathogenic mechanism [52-54]. Importantly, these studies have demonstrated that the effect of the NMDAR autoantibodies can be partially ameliorated with pretreatment using the Ephrin-B2 receptor-ligand. This could represent an important adjunctive approach, especially when neuropsychiatric symptoms persist despite extensive immunotherapy.

Nano-level results have been contextualised by interrogation of regional connectivity plus grey and white matter integrity with MRI. The main findings include largely preserved grey matter, a degree of white matter damage, but widespread disruption of network connectivity $[55,56]$. A network model of brain dysfunction provides a credible synthesis of how changes at the level of synaptic organisation can lead to wide ranging clinical manifestations in the absence of major abnormalities on routine clinical brain imaging. The role of white matter abnormalities hints at effects via glia or perhaps bystander inflammation, and indeed oligodendrocytes do express NMDARs [57]. Alongside these, the development of simple predictive clinical tools such as the anti-NMDAR Encephalitis One-year Functional Status (NEOS) Score and the Clinical Assessment Scale in Autoimmune Encephalitis (CASE), to predict outcomes and trajectories, respectively, is an important step to clinically ground a potentially molecular approach [58, 59]. Collectively, these studies set the scene for precision brain-targeted therapies, in both acute and convalescent phases. They also reinforce the need for early diagnosis and treatment to prevent disease progression during which the possibility of reversibility reduces alongside an increased likelihood of longer term cognitive burden and psychosocial dysfunction.

\section{Distinctive features of LGI1-antibody encephalitis}

Antibodies targeting the voltage-gated potassium channel (VGKC) were originally described in three neurological syndromes: LE—a primarily CNS disorder; neuromyotonia-a predominantly peripheral nervous system (PNS) disorder characterised by peripheral nerve hyperexcitability, muscle cramps, and dysautonomia; and Morvan's syndrome-an overlap syndrome with clear evidence of both CNS and PNS manifestations [60]. A radioimmunoprecipitation assay with $\alpha$-dendrotoxin-labelled VGKCs extracted from mammalian brain lysates was used to detect antibodies to the VGKC. Subsequently, it was discovered that, in fact, these antibodies bound to proteins which were often complexed with the VGKCs: LGI1, contactin-associated protein 2 (CASPR2) and, more rarely, contactin-2 [60, 61] (Fig. 3a). VGKC antibodies which do not bind to one of these proteins (often termed 'double negative') are far more common than LGI1 or CASPR2-reactivities [62, 63], are not associated with a defined immunotherapy-responsive clinical syndrome, have low syndrome specificity, and appear to target cytosolic epitopes unrelated to disease pathogenesis [60, 64-66]. In addition to this issue around specificity of VGKC-antibodies, the VGKC assay fails to detect a number of LGI and CASPR2-specific autoantibodies, meaning that it also has reduced sensitivity. Taken together, these findings indicate that VGKC-antibody testing is clinically obsolete and has no place in routine diagnostic laboratories. Rather, patients with a suggestive clinical presentation should be specifically tested for LGI1 or CASPR2 antibodies.

LGI1-antibody encephalitis is most common in the elderly with a significant male preponderance $[63,67]$. There is an annual incidence of approximately 1-2 per 

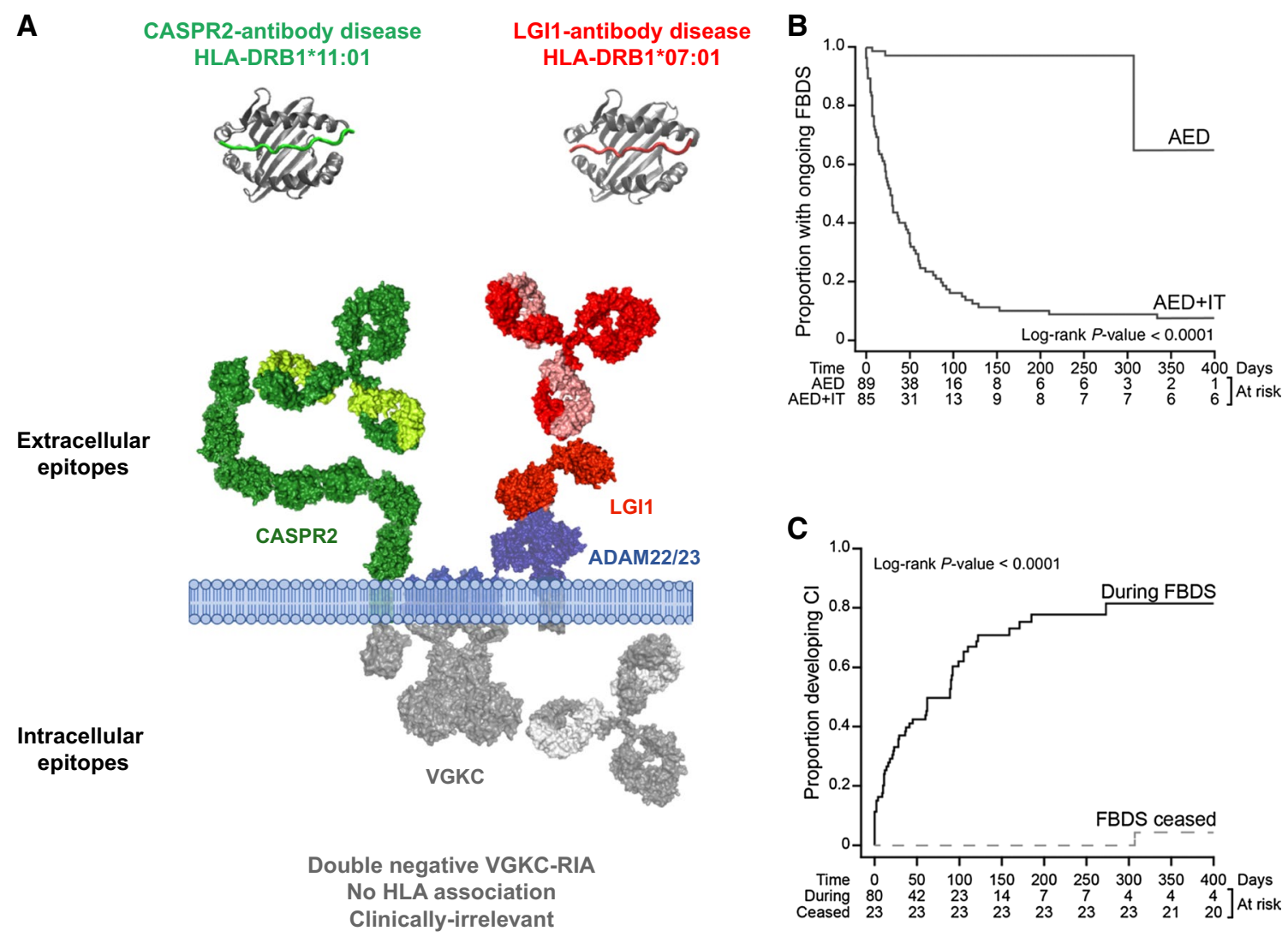

Fig. 3 Genetic, biochemical and therapeutic aspects of LGI1, CASPR2 and double-negative voltage-gated potassium channelcomplex antibodies. a CASPR2 and LGI1 are cell-surface-exposed proteins complexed with voltage-gated potassium channels (VGKC). LGI1 is a secreted protein which binds a disintregin and metalloprotease (ADAM) 22 and 23. The patients typically have immunotherapy-responsive diseases with strong HLA associations. In contrast, patients with VGKC-complex antibodies but without LGI1 or CASPR2 reactivities frequently bind intracellular components, do not

million per year (Irani and Waters, unpublished observations) [67]. Genetic studies have shown that around 90\% of patients with LGI1 antibodies from both Caucasian and Asian cohorts [68-70] carry the human leukocyte antigen (HLA) DRB*07:01.

The two cardinal clinical features of LGI1-antibody encephalitis are seizures and cognitive impairment $[60,61$, 67]. The pathognomonic seizure syndrome for this condition is termed faciobrachial dystonic seizures (FBDS) and has only been recognised in association with LGI1 antibodies to date. This specificity may be akin to the stereotyped complexity of movement disorders and psychopathology closely associated with NMDAR-antibody encephalitis. FBDS refer to brief stereotyped events, most commonly involving the hemiface and ipsilateral arm which occur at a median of 50 times per day at disease nadir $[71,72]$. They are associated with classically epileptic ictal features such as speech arrest, agitation, fear, and automatisms [71, 72]. FBDS often have specific HLA associations and do not have characteristic immunotherapy-responsive clinical associations. b Faciobrachial dystonic seizures (FBDS) are highly responsive to immunotherapy (IT) but not to antiepileptic drugs (AED) alone. c Often, FBDS precede the onset of cognitive impairment. Achieving cessation of FBDS usually prevents progression to cognitive impairment. $\mathbf{b}$ and $\mathbf{c}$ Reproduced with permission from [8]. RIA radioimmunoassay, $A E D$ antiepileptic drug, $I T$ immunotherapy, FBDS faciobrachial dystonic seizures, $C I$ cognitive impairment

precede the development of the cognitive impairment seen in patients with LGI1 antibodies which predominantly involves episodic memory and executive function [27, 72-74]. Other frequent focal seizure semiologies which may occur concurrently with, or in the absence of FBDS, include thermal sensations, body shuddering, motor automatisms, gelastic seizures, and paroxysmal dizzy spells [27, 62, 75-77]. Generalised tonic-clonic seizures are uncommon and usually manifest in the later stages of disease. Importantly, focal seizures - in particular FBDS - are often the first feature of this illness. Hence, their early clinical recognition is paramount prior to the development of a fulminant encephalitic syndrome.

Ancillary investigations may be non-contributory, with EEG often being non-specific and over $50 \%$ of patients having normal MRI and CSF analysis [8, 27, 72, 75]. This highlights the importance of the syndrome being a predominantly clinical diagnosis confirmed by detection of 
LGI1-specific antibodies in the serum, and at a lower frequency in CSF [27]. Where present, ancillary findings may include serum hyponatraemia and MRI evidence of medial temporal swelling during the acute presentation, with longer term development of mesial temporal sclerosis [27, 60, 61, 75]. Exclusively in patients with FBDS, basal ganglia signal changes contralateral to the side of clinical involvement are well described [62, 72, 73, 78, 79]. LGI1 antibodies only rarely associate with tumours, usually thymomas, which are more common in the patients with both LGI1 and CASPR2 antibodies [62].

LGI1-antibody encephalitis is most convincingly demonstrated to be an immunotherapy-responsive clinical syndrome by a large cohort of patients with FBDS who had refractory seizures when treated with (often several) antiepileptic drugs alone [8]. By contrast, $90 \%$ had a favourable response to the initiation of immunotherapy, which was often very rapid, sometimes occurring a few days after commencement of corticosteroids [8, 62] (Fig. 3b). As FBDS and other focal seizure syndromes commonly precede the onset of cognitive symptoms, their clinical recognition provides a critical therapeutic window to expedite diagnosis and initiation of immunotherapy, with cessation of FBDS shown to prevent the long-term functionally impairing sequelae of cognitive impairment (Fig. 3c) [8]. In addition, rapid corticosteroid withdrawal often appears to predispose to early relapses [27, 72]. By contrast, our clinical observation is that patients who receive longer term immunotherapies, have very few relapses. However, as only small numbers of reported patients have been administered chronic immunosuppression with steroid sparing agents, such as rituximab and cyclophosphamide, the therapeutic efficacy of these agents is currently difficult to more formally determine $[80$, 81].

LGI1- and CASPR2-antibody encephalitis syndromes share significant overlap with regard to clinical and radiological phenotypes (Table 2), yet patients with CASPR2 antibodies tend towards the neuromyotonia and Morvan's phenotypes, and often have underlying thymomas [81, 82]. The more precise phenotypic differences await formal description although neuropathic pain syndromes appear to be more common in patients with CASPR 2 antibodies, and, to date, these patients have not been reported to have FBDS without concomitant LGI1 antibodies.

\section{Differential diagnoses}

While viral encephalitis may be considered in the differential diagnosis of a patient with an acute-onset encephalopathy, its presentation differs from $\mathrm{AE}$ with a higher likelihood of fevers, CSF inflammation, and the absence of the signature neuropsychiatric, seizure, and movement disorder manifestations seen in patients with LGI1- or NMDARantibody encephalitis [7]. Differential diagnoses apart from established neuronal surface antibody syndromes and seronegative AE include rare CNS inflammatory disorders such as Hashimoto's encephalopathy, Rasmussen's encephalitis, Bickerstaff's encephalitis, and progressive encephalomyelitis with rigidity and myoclonus [28], as well as prion disease such as Creutzfeldt-Jakob disease [83]. Drugs which result in pharmacological disruption of the NMDAR, such as ketamine, may present similar to NMDAR-antibody encephalitis [35]. Recent expert consensus suggests that AE should be considered in patients with subacute memory impairment and psychiatric symptoms, plus at least one of the following: new focal CNS findings, seizures without an alternate aetiology, MRI consistent with encephalitis, and exclusion of alternative diagnoses [28].

\section{Therapeutic paradigms in autoimmune encephalitis}

Multicentre observational studies involving relatively large cohorts of patients with NMDAR- and LGI1-antibody encephalitis show intrinsic methodological biases, but highlight common themes in therapeutic efficacy and outcomes, which we can reasonably extrapolate to the treatment of other forms of $\mathrm{AE}[3,84]$.

First-line therapy is often in the form of pulsed intravenous methylprednisolone (often followed by high-dose oral prednisone), plus plasmapheresis and/or intravenous immunoglobulin $[7,16]$. In addition, early tumour surveillance is recommended as tumour-directed therapy can be important $[6,16,40]$. Failure to respond to first-line agents should lead to therapy escalation including further steroids/plasmapheresis plus consideration of second-line therapies including rituximab or cyclophosphamide $[4,29,84,85]$. The interval between waiting for first-line therapy to take effect and commencing second-line therapy is debated, and may be reasonably dictated by the severity of presentation, the degree and rate of improvement, and the relative clinical experience of different centres. However, a critical theme in the treatment of AE is that the early institution of immunotherapy is closely linked to reducing long-term sequelae and relapses, and improving outcomes in the short and longer terms $[8$, $12,16,80,84]$. A minority of patients remain refractory to second-line therapy and in a small number of these patients, case reports and case series have highlighted the possible use of third-line immunotherapies such as tocilizumab and bortezomib [86, 87]. These principles are illustrated in a proposed therapeutic algorithm (Fig. 4) but currently lack a robust immunomechanism-based set of concepts for the choice of immunotherapy. 


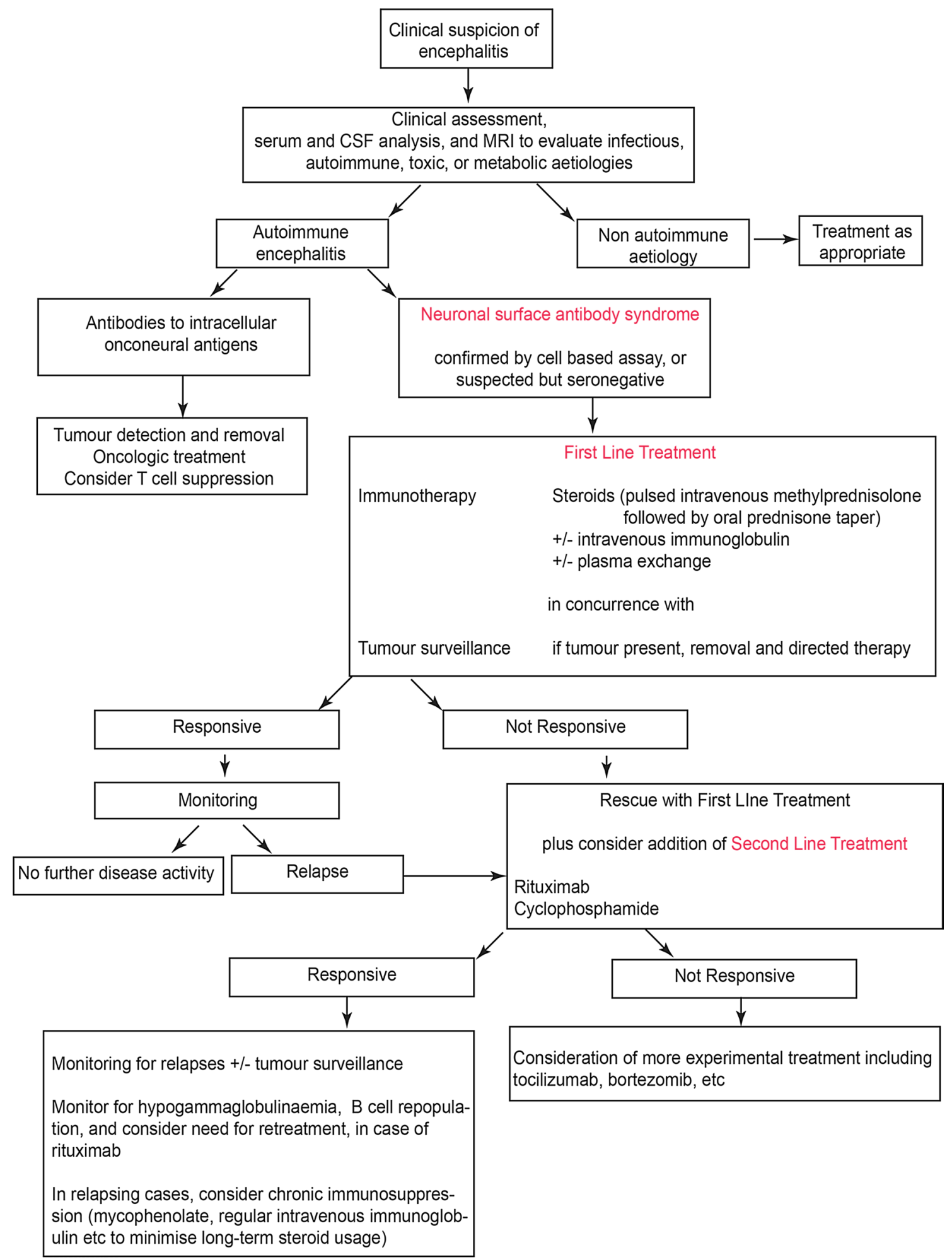

Fig. 4 A diagnostic and therapeutic approach to suspected autoimmune encephalitis Adapted with permission from [7] 
A

Cross-linking and internalisation

Classical complement pathway activation

Direct modulation/block

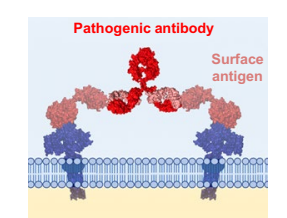

B

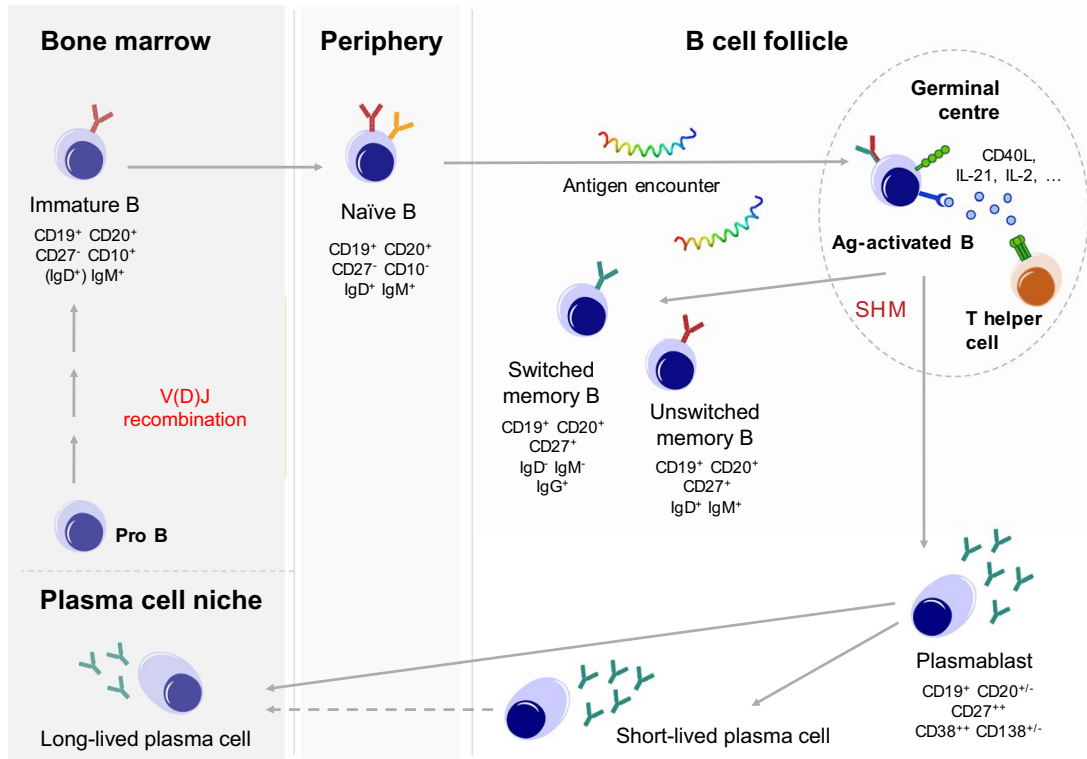

Fig. 5 Potential pathogenic mechanisms of neuronal surface antibodies and B cell lineages underlying generation of antibody-secreting cells. a Antibodies against neuronal surface epitopes can mediate pathogenic effects through multiple mechanisms which include crosslinking and internalisation of the target, fixation of C1q and activation of the classical complement pathway, and direct interference with channel function including pharmacological-type block. b B cells are formed from haematopoietic stem cells in the bone marrow and undergo recombination of $\mathrm{V}, \mathrm{D}$ and $\mathrm{J}$ immunoglobulin genes to generate a functional $\mathrm{B}$ cell receptor. They enter peripheral blood becoming a naïve $\mathrm{B}$ cell, and in lymphatic tissue encounter cognate antigen, leading to B cell activation and generation of germinal centres. In

\section{Proposed pathophysiological mechanisms of action of autoantibodies}

Several in vitro and in vivo studies demonstrate potential pathogenic mechanisms of action by which neuronal surface antibodies may manifest their deleterious downstream effects. Broadly, the predominant mechanisms are target internalisation and complement activation (Fig. 5).

NMDAR IgG autoantibodies have been shown to exert a highly selective and concentration-dependent reduction of postsynaptic clusters of NMDAR in hippocampal neurons which has been observed in vitro and in vivo [88]. This is likely due to the antibody-induced internalisation of surfaceexpressed NMDARs [5, 34, 89, 90]. Removal of the antibodies restores the surface NMDARs, suggesting that this process is reversible, consistent with the observed improvements of patients after immunotherapy, and the absence of neuronal loss in imaging and histopathology studies. Similar phenomena of receptor internalisation have been noted with AMPAR, glycine receptor, and $\mathrm{GABA}_{\mathrm{A}} \mathrm{R}$ antibodies germinal centres, B cells process antigen and present it as peptide on surface MHC molecules to T-helper cells, which in turn provide support for the activated B cells. During the process of affinity maturation, B cells undergo somatic hypermutation leading to a diversity of antigen-specific B cell receptors. Alongside this, the immunoglobulin class often switches from IgM to IgG. This reaction generates memory B cells, as well as antibody-secreting cells in the periphery (plasmablasts). Antibody-secreting cells vary in their longevity and migration back to the bone marrow to a survival niche and are associated with long-term antibody secretion. Reproduced with permission from [102]

[91-93], but not $\mathrm{GABA}_{\mathrm{B}} \mathrm{R}$ antibodies [94]. In addition, using the soluble LGI1 protein and its known receptor ADAM22, we recently showed that internalisation of the LGI1-ADAM22 complex could be mediated by LGI1 antibodies $[8,91]$.

Finally, complement deposition may be a pathogenic mechanism in select cases. By contrast to the IgG4-dominant antibodies which target LGI1, CASPR2, and IgLON5, other pathogenic neuroglial surface receptor antibodies are of the IgG1 subclass. IgG1 antibodies have the ability to activate complement [40]. This is of interest because despite the majority of LGI1 antibodies being of the IgG4 subclass, a proportion of patients with LGI1 IgG1 antibodies are overrepresented in those with cognitive impairment, suggesting that some irreversible sequelae in LGI1-antibody encephalitis may be associated with complement-mediated effects [8]. These questions are not likely to be directly addressed in future post-mortem studies, given the pleasingly low contemporary mortality associated with these diseases. Hence, in vitro studies and in vivo imaging of humans may be more 
informative opportunities to more formally model these observations.

\section{How is autoimmunity initiated in these patients?}

The studies outlined above address possible mechanisms by which pathogenic autoantibodies exert their functional effects. However, they do not identify the original initiating autoimmune process. Below, we will explore identified triggers including tumours and infections, underlying genetic susceptibilities, and what is known about the production of pathogenic antibodies across stages of B cell development. These immunological observations aim to inform mechanisms underlying the propagation and the cause of these diseases.

Paraneoplastic associations are present in several neuronal surface antibody syndromes. In particular, the frequent relationship between NMDAR-antibody encephalitis and teratomas generates a compelling line of investigation. Histopathological studies of patient teratomas have highlighted dense B and T cell infiltrates, neuroglial NR1 antigen expression plus dysplastic neuronal elements (Fig. 2c) [95-97]. These observations imply ectopic antigen expression and reactive germinal centre reactions in NMDAR-antibody encephalitis-teratomas, which may be important for disease induction [97]. Furthermore, and more definitively pathogenic, teratoma explants can produce the NMDAR antibodies in vitro, suggesting intratumoural B cells have the capacity to secrete pathogenic antibodies [97]. Taken together with the time-dependent clinical efficacy of oophorectomy in improving outcomes $[16,34,40]$, this suggests that the initiation of the immune process occurs in the peripheral compartments with intratumoural synthesis, and the subsequent passage of B cells to the circulation, and the intrathecal space. Indeed, this model aligns well with the consistently higher serum levels of autoantibodies in these conditions $[24,25,27,40]$.

In support of this peripheral-to-central flux of the immune process, a recent clinical observation has shed light on the exposure of brain antigens to the immune system as a potential trigger of AE. Patients with proven herpes simplex virus encephalitis (HSVE) have been noted to develop a clinical worsening a few weeks after initiation of their HSVE. This worsening is associated with the de novo generation of autoantibodies [41, 42, 98, 99]. Around 50\% of patients seroconvert, with generation of several surface neuronal autoantibodies during the first few months of HSVE [25]. Around $50 \%$ of the autoantibodies had NMDAR reactivity, but other non-NMDAR targets have also been found, including D2R, AMPAR, and $\mathrm{GABA}_{\mathrm{A}}$ receptor antibodies plus surface neuronal binding without an identified target $[3,25$,
42, 100]. HSVE animal models have mimicked this seroconversion with the generation of serum NMDAR antibodies after intranasal HSV inoculation [101]. There have also been reports of NMDAR antibodies following other CNS viral infections, which argue against classical molecular mimicry being a dominant mechanism in this natural human immunisation paradigm [100]. Indeed, generic viral nucleic acid mimics are known to efficiently stimulate circulating B cells to produce antigen-specific autoantibodies [97, 102], adding to the evidence that viral infections may contribute directly to autoimmunity. A parsimonious explanation is that neuronal damage, the inflammatory milieu, and the virus directly may expose previously sequestered brain antigens to reactive lymphocytes within draining cervical lymph nodes, thereby overcoming the status quo of CNS immune privilege and generating brain-specific autoantibodies. Yet, how the antigen-specific lymphocytes originally escape immunological tolerance has been studied in only a few patients to date.

We have identified naïve pre-germinal centre B cells capable of differentiating to secrete aquaporin-4-specific autoantibodies in patients with another CNS autoantibodymediated condition, neuromyelitis optica [102]. Therefore, preformed B cells can possess antigen-specific reactivity. This may also be the case in NMDAR-antibody encephalitis where some monoclonal NR1-specific antibodies derived from patient CSF B cells showed no or few somatic hypermutations [26]; these antibodies were able to bind NMDARs and mediate functional effects in vitro [103]. This also suggests that a naïve repertoire of antigen-specific B cells is present in patients. However, by contrast to aquaporin- 4 antibodies, this initial report suggests that the NMDAR antibodies do not appear to mutate heavily, even once in the intrathecal space. Yet, the teratoma histology provides strong evidence for a germinal centre, a classical site of hypermutation. Circulating NR1-IgG concentrations are proportional to the ex vivo capacity of patient B cells to secrete NR1 IgGs, again suggesting cells derived from germinal centre spillover account for serum NR1 IgGs [97]. Therefore, the relative roles of naïve B cells and hypermutated memory B cells remain to be established and may have implications for optimal tailored therapies or identification of 'at risk' patients.

Studies in patients with LGI1 and CASPR2 antibodies have also implied a role for germinal centre reactions, via the identification of strong and dichotomous genetic susceptibilities. Over $90 \%$ of LGI1-antibody-positive encephalitis patients, of both East Asian and Caucasian extraction, have the HLA-DRB $1 * 07: 01$ allele [68-70], while patients with CASPR2-antibody encephalitis have a marked overrepresentation of HLA DRB1*11:01 [70]. There is a strong correlation between IgLON5 antibodies and HLADRB 1*10:01-DQB1*05:01 [104], and a weak association with NMDAR-antibody encephalitis and the HLA-B*07:02 allele [105]. While none of the alleles are likely to be the 
sole susceptibility factor involved, these associations imply restricted $\mathrm{T}-\mathrm{B}$ cell interactions are critical in the generation of autoantibodies. In addition, we are finding that these HLA associations are absent in patients with autoantibodies but without clinically compatible syndromes [70], suggesting that they may emerge as useful ancillary tools in clinical diagnosis.

\section{Conclusion}

Many of the early clinical observations in AE have been further refined to permit the accurate recognition of distinctive clinical phenotypes. This serves as a starting point not only to guide clinical practice, but also to inform focussed laboratory lines of enquiry. The relative rarity of these conditions on a population level remains a challenge to research, and highlights the notion that international and multicentre collaborations remain essential to move the field forward. $\mathrm{AE}$ is now identified as an important and previously underrecognised cause of CNS inflammation-it is highly treatable, and early diagnosis and initiation of immunotherapy are paramount to optimise outcomes. The field is now entering a more mature phase of research with advanced approaches in imaging, molecular immunology, and neuroscience. This will ideally permit a more cohesive understanding of aetiology and pathogenesis, and ultimately advance precision therapy in the future.

Acknowledgements The authors would like to thank colleagues in the Oxford Autoimmune Neurology Group for their assistance with and production of figures and data which contributed to this article: Antonio Berretta, Jeanne May May Tan, James Varley, Anne-Kathrin Kienzler and Victor Mgbachi.

Funding SR is supported by the National Health and Medical Research Council (Australia) (APP1141169) on an Early Career Fellowship (2018). AAD is the recipient of a Wellcome Trust clinical research training fellowship (205126/Z/16/Z) and of a 2017 British Medical Association (BMA) Foundation Margaret Temple grant, and is supported by the National Institute for Health Research (NIHR) Oxford Biomedical Research Centre and NIHR Oxford Health Biomedical Research Centre. SRI is supported by the Wellcome Trust (104079/Z/14/Z), the UCB-Oxford University Alliance, BMA Research Grants-Vera Down grant (2013) and Margaret Temple (2017) and Epilepsy Research UK (P1201). The research was funded/supported by the National Institute for Health Research (NIHR) Oxford Biomedical Research Centre [(BRC); the views expressed are those of the author(s) and not necessarily those of the NHS, the NIHR or the Department of Health]. SRI is a co-applicant and receives royalties on patent application WO/2010/046716 (U.K. patent no., PCT/GB2009/051441) entitled 'Neurological Autoimmune Disorders'. The patent has been licensed to Euroimmun AG for the development of assays for LGI1 and other VGKC-complex antibodies. He has received honoraria from UCB, MedImmun, ADC therapeutics and Medlink Neurology. Patrick Waters is a named inventor on patents for antibody assays and has received royalties. He has received honoraria from Biogen Idec, Mereo Biopharma, Retrogenix, UBC and Euroimmun AG; travel grants from the Guthy-Jackson Charitable Foundation; and research funding from Euroimmun AG.

\section{Compliance with ethical standards}

Conflicts of interest SR is the recipient of an National Health and Medical Research Council (Australia) Early Career Fellowship (APP1141169 - 2018), and has received research funding from the Petre Foundation (Australia), the Brain Foundation (Australia), and has served as a non-remunerated consultant on an advisory board for UCB. AAD is the recipient of a Wellcome Trust clinical research training fellowship (205126/Z/16/Z) and of a 2017 British Medical Association (BMA) Foundation Margaret Temple grant, and is supported by the National Institute for Health Research (NIHR) Oxford Biomedical Research Centre and NIHR Oxford Health Biomedical Research Centre. SRI is supported by the Wellcome Trust (104079/Z/14/Z), the UCBOxford University Alliance, BMA Research Grants- Vera Down grant (2013) and Margaret Temple (2017) and Epilepsy Research UK (P1201). The research was funded /supported by the National Institute for Health Research (NIHR) Oxford Biomedical Research Centre (BRC; The views expressed are those of the author(s) and not necessarily those of the NHS, the NIHR or the Department of Health). SRI is a coapplicant and receives royalties on patent application WO/2010/046716 (U.K. patent no., PCT/GB2009/051441) entitled 'Neurological Autoimmune Disorders'. The patent has been licensed to Euroimmun AG for the development of assays for LGI1 and other VGKC-complex antibodies. He has received honoraria from $\mathrm{UCB}$, MedImmun, ADC therapeutics and Medlink Neurology. PW is a named inventor on patents for antibody assays and has received royalties. He has received honoraria from Biogen Idec, Mereo Biopharma, Retrogenix, UBC and Euroimmun AG; travel grants from the GuthyJackson Charitable Foundation; and research funding from Euroimmun AG.

Open Access This article is distributed under the terms of the Creative Commons Attribution 4.0 International License (http://creativeco mmons.org/licenses/by/4.0/), which permits unrestricted use, distribution, and reproduction in any medium, provided you give appropriate credit to the original author(s) and the source, provide a link to the Creative Commons license, and indicate if changes were made.

\section{References}

1. Corsellis JA, Goldberg GJ, Norton AR (1968) "Limbic encephalitis" and its association with carcinoma. Brain 91(3):481-496

2. Irani SR, Gelfand JM, Al-Diwani A, Vincent A (2014) Cellsurface central nervous system autoantibodies: clinical relevance and emerging paradigms. Ann Neurol 76(2):168-184

3. Dalmau J, Graus F (2018) Antibody-mediated encephalitis. N Engl J Med 378(9):840-851

4. Ramanathan S, Mohammad SS, Brilot F, Dale RC (2014) Autoimmune encephalitis: recent updates and emerging challenges. J Clin Neurosci 21(5):722-730

5. Bien CG, Vincent A, Barnett MH et al (2012) Immunopathology of autoantibody-associated encephalitides: clues for pathogenesis. Brain 135:1622-1638

6. Lancaster E, Dalmau J (2012) Neuronal autoantigens-pathogenesis, associated disorders and antibody testing. Nat Rev Neurol 8(7):380-390

7. Ramanathan S, Irani SR (2018) Autoantibody-mediated forms of encephalitis. In: Reference module in neuroscience and biobehavioral psychology. Elsevier. ISBN 9780128093245 
8. Thompson J, Bi M, Murchison AG et al (2018) The importance of early immunotherapy in patients with faciobrachial dystonic seizures. Brain 141(2):348-356

9. Irani SR, Vincent A, Schott JM (2011) Autoimmune encephalitis. BMJ 342:d1918

10. Varley J, Vincent A, Irani SR (2015) Clinical and experimental studies of potentially pathogenic brain-directed autoantibodies: current knowledge and future directions. J Neurol 262(4):1081-1095

11. Irani SR, Bien CG, Lang B (2011) Autoimmune epilepsies. Curr Opin Neurol 24(2):146-153

12. Damato V, Balint B, Kienzler AK, Irani SR (2018) The clinical features, underlying immunology, and treatment of autoantibodymediated movement disorders. Mov Disord 33(9):1376-1389

13. Vincent A, Irani SR, Lang B (2011) Potentially pathogenic autoantibodies associated with epilepsy and encephalitis in children and adults. Epilepsia 52(Suppl 8):8-11

14. Haselmann H, Mannara F, Werner C et al (2018) Human autoantibodies against the AMPA receptor subunit GluA2 induce receptor reorganization and memory dysfunction. Neuron 100(1):91-105

15. Dubey D, Pittock SJ, Kelly CR et al (2018) Autoimmune encephalitis epidemiology and a comparison to infectious encephalitis. Ann Neurol 83(1):66-177

16. Titulaer MJ, McCracken L, Gabilondo I et al (2013) Treatment and prognostic factors for long-term outcome in patients with anti-NMDA receptor encephalitis: an observational cohort study. Lancet Neurol 12(2):157-165

17. Machado S, Pinto AN, Irani SR (2012) What should you know about limbic encephalitis? Arq Neuropsiquiatr 70(10):817-822

18. Waters P, Reindl M, Saiz A et al (2016) Multicentre comparison of a diagnostic assay: aquaporin-4 antibodies in neuromyelitis optica. J Neurol Neurosurg Psychiatry 87(9):1005-1015

19. Waters P, Komorowski L, Woodhall M et al (2019) A multicenter comparison of MOG-IgG cell-based assays. Neurology 92(11):e1250-e1255

20. Jezequel J, Johansson EM, Dupuis JP et al (2017) Dynamic disorganization of synaptic NMDA receptors triggered by autoantibodies from psychotic patients. Nat Commun 8(1):1791

21. McCracken L, Zhang J, Greene M et al (2017) Improving the antibody-based evaluation of autoimmune encephalitis. Neurol Neuroimmunol Neuroinflamm 4(6):e404

22. Jezequel J, Rogemond V, Pollak T et al (2017) Cell- and single molecule-based methods to detect anti- $N$-methyl-D-aspartate receptor autoantibodies in patients with first-episode psychosis from the OPTiMiSE Project. Biol Psychiatry 82(10):766-772

23. Dahm L, Ott C, Steiner J et al (2014) Seroprevalence of autoantibodies against brain antigens in health and disease. Ann Neurol 76(1):82-94

24. Lancaster E, Lai M, Peng X et al (2010) Antibodies to the GABA(B) receptor in limbic encephalitis with seizures: case series and characterisation of the antigen. Lancet Neurol 9(1):67-76

25. Armangue T, Spatola M, Vlagea A et al (2018) Frequency, symptoms, risk factors, and outcomes of autoimmune encephalitis after herpes simplex encephalitis: a prospective observational study and retrospective analysis. Lancet Neurol 17(9):760-772

26. Kreye J, Wenke NK, Chayka M et al (2016) Human cerebrospinal fluid monoclonal $N$-methyl-D-aspartate receptor autoantibodies are sufficient for encephalitis pathogenesis. Brain 139:2641-2652

27. van Sonderen A, Thijs RD, Coenders EC et al (2016) Anti-LGI1 encephalitis: clinical syndrome and long-term follow-up. Neurology 87(14):1449-1456

28. Graus F, Titulaer MJ, Balu R et al (2016) A clinical approach to diagnosis of autoimmune encephalitis. Lancet Neurol 15(4):391-404
29. Lee WJ, Lee ST, Byun JI et al (2016) Rituximab treatment for autoimmune limbic encephalitis in an institutional cohort. Neurology 86(18):1683-1691

30. Armangue T, Titulaer MJ, Sabater L et al (2014) A novel treatment-responsive encephalitis with frequent opsoclonus and teratoma. Ann Neurol 75(3):435-441

31. Gable MS, Sheriff H, Dalmau J et al (2012) The frequency of autoimmune $\mathrm{N}$-methyl-D-aspartate receptor encephalitis surpasses that of individual viral etiologies in young individuals enrolled in the California Encephalitis Project. Clin Infect Dis 54(7):899-904

32. Vitaliani R, Mason W, Ancs B et al (2005) Paraneoplastic encephalitis, psychiatric symptoms, and hypoventilation in ovarian teratoma. Ann Neurol 58(4):594-604

33. Dalmau J, Tuzun E, Wu HY et al (2007) Paraneoplastic anti$\mathrm{N}$-methyl-D-aspartate receptor encephalitis associated with ovarian teratoma. Ann Neurol 61(1):25-36

34. Dalmau J, Gleichman A, Hughes E et al (2008) Anti-NMDAreceptor encephalitis: case series and analysis of the effects of antibodies. Lancet Neurol 7(12):1091-1098

35. Dalmau J, Lancaster E, Martinez-Hernandez E et al (2011) Clinical experience and laboratory investigations in patients with antiNMDAR encephalitis. Lancet Neurol 10(1):63-74

36. Biancheri R, Pessagno A, Baglietto MG et al (2010) Anti-Nmethyl-D-aspartate-receptor encephalitis in a four-year-old girl. J Pediatr 156(2):332-334

37. Okamura H, Oomori N, Uchitomi Y (1997) An acutely confused 15-year-old girl. Lancet 350(9076):488

38. Kamei S, Kuzuhara S, Ishihara M et al (2009) Nationwide survey of acute juvenile female non-herpetic encephalitis in Japan: relationship to anti- $N$-methyl-D-aspartate receptor encephalitis. Intern Med 48(9):673-679

39. Dale RC, Irani SR, Brilot F et al (2009) $N$-methyl-D-aspartate receptor antibodies in pediatric dyskinetic encephalitis lethargica. Ann Neurol 66(5):704-709

40. Irani SR, Bera K, Waters $\mathrm{P}$ et al (2010) $N$-methyl-D-aspartate antibody encephalitis: temporal progression of clinical and paraclinical observations in a predominantly non-paraneoplastic disorder of both sexes. Brain 133:1655-1667

41. Hacohen Y, Deiva K, Pettingill P et al (2014) N-methyl-D-aspartate receptor antibodies in post-herpes simplex virus encephalitis neurological relapse. Mov Disord 29(1):90-96

42. Armangue T, Leypoldt F, Malaga I et al (2014) Herpes simplex virus encephalitis is a trigger of brain autoimmunity. Ann Neurol 75(2):317-323

43. Balint B, Vincent A, Meinck HM et al (2018) Movement disorders with neuronal antibodies: syndromic approach, genetic parallels and pathophysiology. Brain 141(1):13-36

44. Mohammad SS, Fung VSC, Grattan-Smith P et al (2014) Movement disorders in children with anti-NMDAR encephalitis and other autoimmune encephalopathies. Mov Disord 29(12):1539-1542

45. Baizabal-Carvallo JF, Stocco A, Muscal E et al (2013) The spectrum of movement disorders in children with anti-NMDA receptor encephalitis. Mov Disord 28(4):543-547

46. Varley JA, Webb AJS, Balint B et al (2018) The movement disorder associated with NMDAR antibody-encephalitis is complex and characteristic: an expert video-rating study. J Neurol Neurosurg Psychiatry 90(6):724-726

47. Al-Diwani A, Handel A, Townsend L et al (2019) The psychopathology of NMDAR-antibody encephalitis in adults: a systematic review and phenotypic analysis of individual patient data. Lancet Psychiatry 6(3):235-246

48. Warren N, Siskind D, O'Gorman C (2018) Refining the psychiatric syndrome of anti- $N$-methyl-D-aspartate receptor encephalitis. Acta Psychiatr Scand 138(5):401-408 
49. Gibson LL, Pollak TA, Blackman G et al (2019) The psychiatric phenotype of anti-NMDA receptor encephalitis. J Neuropsychiatry Clin Neurosci 31(1):70-79

50. Al-Diwani AAJ, Pollak TA, Irani SR et al (2017) Psychosis: an autoimmune disease? Immunology 152(3):388-401

51. Armangue T, Santamaria J, Dalmau J (2015) When a serum test overrides the clinical assessment. Neurology 84(13):1379-1381

52. Mikasova L, De Rossi P, Bouchet D et al (2012) Disrupted surface cross-talk between NMDA and Ephrin-B2 receptors in anti-NMDA encephalitis. Brain 135:1606-1621

53. Planaguma J, Haselmann H, Mannara F et al (2016) EphrinB2 prevents $N$-methyl-D-aspartate receptor antibody effects on memory and neuroplasticity. Ann Neurol 80(3):388-400

54. Ladepeche L, Planaguma J, Thakur S et al (2018) NMDA receptor autoantibodies in autoimmune encephalitis cause a subunit-specific nanoscale redistribution of NMDA receptors. Cell Rep 23(13):3759-3768

55. Finke C, Kopp UA, Scheel M et al (2013) Functional and structural brain changes in anti- $N$-methyl-D-aspartate receptor encephalitis. Ann Neurol 74(2):284-296

56. Peer M, Pruss H, Ben-Dayan I et al (2017) Functional connectivity of large-scale brain networks in patients with antiNMDA receptor encephalitis: an observational study. Lancet Psychiatry 4(10):768-774

57. Karadottir R, Cavelier P, Bergersen LH et al (2005) NMDA receptors are expressed in oligodendrocytes and activated in ischaemia. Nature 438(7071):1162-1166

58. Balu R, McCracken L, Lancaster E et al (2019) A score that predicts 1-year functional status in patients with anti-NMDA receptor encephalitis. Neurology 92(3):e244-e252

59. Lim JA, Lee ST, Moon J et al (2019) Development of the clinical assessment scale in autoimmune encephalitis. Ann Neurol 85(3):352-358

60. Irani SR, Alexander S, Waters P et al (2010) Antibodies to Kv1 potassium channel-complex proteins leucine-rich, glioma inactivated 1 protein and contactin-associated protein- 2 in limbic encephalitis. Morvan's syndrome and acquired neuromyotonia. Brain 133(9):2734-2748

61. Lai M, Huijbers MG, Lancaster E et al (2010) Investigation of LGI1 as the antigen in limbic encephalitis previously attributed to potassium channels: a case series. Lancet Neurol 9(8):776-785

62. Gadoth A, Pittock SJ, Dubey D et al (2017) Expanded phenotypes and outcomes among 256 LGI1/CASPR2-IgG-positive patients. Ann Neurol 82(1):79-92

63. Lopez-Chiriboga AS, Klein C, Zekeridou A et al (2018) LGI1 and CASPR2 neurological autoimmunity in children. Ann Neurol 84(3):473-480

64. Klein CJ, Lennon VA, Aston PA et al (2013) Insights from LGI1 and CASPR2 potassium channel complex autoantibody subtyping. JAMA Neurol 70(2):229-234

65. Lang B, Makuch M, Moloney T et al (2017) Intracellular and non-neuronal targets of voltage-gated potassium channel complex antibodies. J Neurol Neurosurg Psychiatry 88(4):353-361

66. van Sonderen A, Schreurs MW, de Bruijn MA et al (2016) The relevance of VGKC positivity in the absence of LGI1 and Caspr2 antibodies. Neurology 86:1692-1699

67. Ramanathan S, Irani SR (2018) Anti-LGI1 encephalitis. Medlink neurology. MedLink Corporation, San Diego

68. Kim TJ, Lee ST, Moon J et al (2017) Anti-LGI1 encephalitis is associated with unique HLA subtypes. Ann Neurol 81(2):183-192

69. van Sonderen A, Roelen DL, Stoop JA et al (2017) Anti-LGI1 encephalitis is strongly associated with HLA-DR7 and HLADRB4. Ann Neurol 81(2):193-198
70. Binks S, Varley J, Lee W et al (2018) Distinct HLA associations of LGI1 and CASPR2-antibody diseases. Brain 141(8):2263-2271

71. Irani SR, Michell AW, Lang B et al (2011) Faciobrachial dystonic seizures precede Lgi1 antibody limbic encephalitis. Ann Neurol 69(5):892-900

72. Irani SR, Stagg CJ, Schott JM et al (2013) Faciobrachial dystonic seizures: the influence of immunotherapy on seizure control and prevention of cognitive impairment in a broadening phenotype. Brain 136:3151-3162

73. Finke C, Pruss H, Heine J et al (2017) Evaluation of cognitive deficits and structural hippocampal damage in encephalitis with leucine-rich, glioma-inactivated 1 antibodies. JAMA Neurol 74(1):50-59

74. Miller TD, Chong TT, Davies AM et al (2017) Focal CA3 hippocampal subfield atrophy following LGI1 VGKC-complex antibody limbic encephalitis. Brain 140(5):1212-1219

75. Aurangzeb S, Symmonds M, Knight RK et al (2017) LGI1-antibody encephalitis is characterised by frequent, multifocal clinical and subclinical seizures. Seizure 50:14-17

76. Naasan G, Irani SR, Bettcher BM et al (2014) Episodic bradycardia as neurocardiac prodrome to voltage-gated potassium channel complex/leucine-rich, glioma inactivated 1 antibody encephalitis. JAMA Neurol 71(10):1300-1304

77. Bakpa OD, Reuber M, Irani SR (2016) Antibody-associated epilepsies: clinical features, evidence for immunotherapies and future research questions. Seizure 41:26-41

78. Flanagan EP, Kotsenas AL, Britton JW et al (2015) Basal ganglia T1 hyperintensity in LGI1-autoantibody faciobrachial dystonic seizures. Neurol Neuroimmunol Neuroinflamm 2(6):e161

79. Navarro V, Kas A, Apartis E et al (2016) Motor cortex and hippocampus are the two main cortical targets in LGI1-antibody encephalitis. Brain 139:1079-1093

80. Irani SR, Gelfand JM, Bettcher BM et al (2014) Effect of rituximab in patients with leucine-rich, glioma-inactivated 1 antibody-associated encephalopathy. JAMA Neurol 71(7):896-900

81. van Sonderen A, Schreurs MW, Wirtz PW et al (2016) From VGKC to LGI1 and Caspr2 encephalitis: the evolution of a disease entity over time. Autoimmun Rev 15(10):970-974

82. Irani SR, Pettingill P, Kleopa KA et al (2012) Morvan syndrome: clinical and serological observations in 29 cases. Ann Neurol 72(2):241-255

83. Grau-Rivera O, Sanchez-Valle R, Saiz A et al (2014) Determination of neuronal antibodies in suspected and definite CreutzfeldtJakob disease. JAMA Neurol 71(1):74-78

84. Nosadini M, Mohammad SS, Ramanathan S et al (2015) Immune therapy in autoimmune encephalitis: a systematic review. Expert Rev Neurother 15(12):1391-1419

85. Dubey D, Blackburn K, Greenberg B et al (2016) Diagnostic and therapeutic strategies for management of autoimmune encephalopathies. Expert Rev Neurother 16(8):937-949

86. Lee WJ, Lee ST, Moon J et al (2016) Tocilizumab in autoimmune encephalitis refractory to rituximab: an institutional cohort study. Neurotherapeutics 13(4):824-832

87. Behrendt V, Krogias C, Reinacher-Schick A et al (2016) Bortezomib treatment for patients with anti-N-methyl-D-aspartate receptor encephalitis. JAMA Neurol 73(10):1251-1253

88. Planaguma J, Leypoldt F, Mannara F et al (2015) Human $\mathrm{N}$-methyl D-aspartate receptor antibodies alter memory and behaviour in mice. Brain 138:94-109

89. Hughes EG, Peng X, Gleichman AJ et al (2010) Cellular and synaptic mechanisms of anti-NMDA receptor encephalitis. J Neurosci 30(17):5866-5875

90. Gleichman AJ, Spruce LA, Dalmau J et al (2012) Anti-NMDA receptor encephalitis antibody binding is dependent on amino 
acid identity of a small region within the GluN1 amino terminal domain. J Neurosci 32(32):11082-11094

91. Lai M, Hughes EG, Peng X et al (2009) AMPA receptor antibodies in limbic encephalitis alter synaptic receptor location. Ann Neurol 65(4):424-434

92. Carvajal-Gonzalez A, Leite MI, Waters P et al (2014) Glycine receptor antibodies in PERM and related syndromes: characteristics, clinical features and outcomes. Brain 137:2178-2192

93. Pettingill P, Kramer HB, Coebergh JA et al (2015) Antibodies to GABAA receptor alpha1 and gamma2 subunits: clinical and serologic characterization. Neurology 84(12):1233-1241

94. Nibber A, Mann EO, Pettingill P et al (2017) Pathogenic potential of antibodies to the GABAB receptor. Epilepsia Open 2(3):355-359

95. Dabner M, McCluggage WG, Bundell C et al (2012) Ovarian teratoma associated with anti-N-methyl D-aspartate receptor encephalitis: a report of 5 cases documenting prominent intratumoral lymphoid infiltrates. Int J Gynecol Pathol 31(5):429-437

96. Day GS, Laiq S, Tang-Wai DR et al (2014) Abnormal neurons in teratomas in NMDAR encephalitis. JAMA Neurol 71(6):717-724

97. Makuch M, Wilson R, Al-Diwani A et al (2018) $N$-methylD-aspartate receptor antibody production from germinal center reactions: therapeutic implications. Ann Neurol 83(3):553-561

98. Mohammad SS, Sinclair K, Pillai S et al (2014) Herpes simplex encephalitis relapse with chorea is associated with autoantibodies to $N$-Methyl-D-aspartate receptor or dopamine-2 receptor. Mov Disord 29(1):117-122

99. Pruss H, Finke C, Holtje M et al (2012) $N$-methyl-D-aspartate receptor antibodies in herpes simplex encephalitis. Ann Neurol 72(6):902-911

100. Pruss H (2017) Postviral autoimmune encephalitis: manifestations in children and adults. Curr Opin Neurol 30(3):327-333

101. Linnoila J, Pulli B, Armangue T et al (2019) Mouse model of anti-NMDA receptor post-herpes simplex encephalitis. Neurol Neuroimmunol Neuroinflamm 6(2):e529

102. Wilson R, Makuch M, Kienzler AK et al (2018) Conditiondependent generation of aquaporin-4 antibodies from circulating B cells in neuromyelitis optica. Brain 141(4):1063-1074

103. Wenke NK, Kreye J, Andrzejak E et al (2019) $N$-methyl-D-aspartate receptor dysfunction by unmutated human antibodies against the NR1 subunit. Ann Neurol 85(5):771-776

104. Gaig C, Graus F, Compta Y et al (2017) Clinical manifestations of the anti-IgLON5 disease. Neurology 88(18):1736-1743

105. Mueller SH, Farber A, Pruss H et al (2018) Genetic predisposition in anti-LGI1 and anti-NMDA receptor encephalitis. Ann Neurol 83(4):863-869

106. Bergink V, Armangue T, Titulaer MJ et al (2015) Autoimmune encephalitis in postpartum psychosis. Am J Psychiatry 172(9):901-908

107. Kayser MS, Titulaer MJ, Gresa-Arribas N et al (2013) Frequency and characteristics of isolated psychiatric episodes in anti- $N$-methyl-D-aspartate receptor encephalitis. JAMA Neurol 70(9):1133-1139

108. Gillinder L, Warren N, Hartel G et al (2019) EEG findings in NMDA encephalitis-a systematic review. Seizure 65:20-24

109. Binks S, Klein CJ, Waters P et al (2018) LGI1, CASPR2 and related antibodies: a molecular evolution of the phenotypes. $\mathrm{J}$ Neurol Neurosurg Psychiatry 89(5):526-534

110. Hutchinson M, Waters P, McHugh J et al (2008) Progressive encephalomyelitis, rigidity, and myoclonus: a novel glycine receptor antibody. Neurology 71(16):1291-1292

111. Mas N, Saiz A, Leite MI et al (2011) Antiglycine-receptor encephalomyelitis with rigidity. J Neurol Neurosurg Psychiatry 82(12):1399-1401
112. McKeon A, Martinez-Hernandez E, Lancaster E et al (2013) Glycine receptor autoimmune spectrum with stiff-man syndrome phenotype. JAMA Neurol 70(1):44-50

113. Ohkawa $T$, Satake $S$, Yokoi $N$ et al (2014) Identification and characterization of $\mathrm{GABA}(\mathrm{A})$ receptor autoantibodies in autoimmune encephalitis. J Neurosci 34(24):8151-8163

114. Petit-Pedrol M, Armangue T, Peng X et al (2014) Encephalitis with refractory seizures, status epilepticus, and antibodies to the GABAA receptor: a case series, characterisation of the antigen, and analysis of the effects of antibodies. Lancet Neurol 13(3):276-286

115. Boronat A, Sabater L, Saiz A et al (2011) GABA(B) receptor antibodies in limbic encephalitis and anti-GAD-associated neurologic disorders. Neurology 76(9):795-800

116. Alexopoulos H, Dagklis IE, Akrivou S et al (2014) Autoimmune encephalitis with GABAB antibodies, thymoma, and GABAB receptor thymic expression. Neurol Neuroimmunol Neuroinflamm 1(4):e39

117. Onugoren MD, Deuretzbacher D, Haensch CA et al (2015) Limbic encephalitis due to GABAB and AMPA receptor antibodies: a case series. J Neurol Neurosurg Psychiatry 86(9):965-972

118. Lancaster E, Martinez-Hernandez E, Titulaer MJ et al (2011) Antibodies to metabotropic glutamate receptor 5 in the Ophelia syndrome. Neurology 77(18):1698-1701

119. Nicoletti F, Bockaert J, Collingridge GL et al (2011) Metabotropic glutamate receptors: from the workbench to the bedside. Neuropharmacology 60(7-8):1017-1041

120. Boronat A, Gelfand JM, Gresa-Arribas N et al (2013) Encephalitis and antibodies to dipeptidyl-peptidase-like protein-6, a subunit of Kv4.2 potassium channels. Ann Neurol 73(1):120-128

121. Tobin WO, Lennon VA, Komorowski L et al (2014) DPPX potassium channel antibody: frequency, clinical accompaniments, and outcomes in 20 patients. Neurology 83(20):1797-1803

122. Piepgras J, Holtje M, Michel K et al (2015) Anti-DPPX encephalitis: pathogenic effects of antibodies on gut and brain neurons. Neurology 85(10):890-897

123. Dale RC, Merheb V, Pillai S et al (2012) Antibodies to surface dopamine-2 receptor in autoimmune movement and psychiatric disorders. Brain 135:3453-3468

124. Sinmaz N, Tea F, Pilli D et al (2016) Dopamine-2 receptor extracellular N-terminus regulates receptor surface availability and is the target of human pathogenic antibodies from children with movement and psychiatric disorders. Acta Neuropathol Commun 4(1): 126

125. Sabater L, Gaig C, Gelpi E et al (2014) A novel non-rapid-eye movement and rapid-eye-movement parasomnia with sleep breathing disorder associated with antibodies to IgLON5: a case series, characterisation of the antigen, and post-mortem study. Lancet Neurol 13(6):575-586

126. Gelpi E, Hoftberger R, Graus F et al (2016) Neuropathological criteria of anti-IgLON5-related tauopathy. Acta Neuropathol 132(4):531-543

127. Honorat JA, Komorowski L, Josephs KA et al (2017) IgLON5 antibody: neurological accompaniments and outcomes in 20 patients. Neurol Neuroimmunol Neuroinflamm 4(5):e385

128. Gresa-Arribas N, Planaguma J, Petit-Pedrol M et al (2016) Human neurexin-3alpha antibodies associate with encephalitis and alter synapse development. Neurology 86(24):2235-2242

129. Berridge G, Menassa DA, Moloney T et al (2018) Glutamate receptor delta2 serum antibodies in pediatric opsoclonus myoclonus ataxia syndrome. Neurology 91(8):e714-e723

130. Al-Diwani A, Linighan R, Perkins C et al (2019) 25 On being autoimmune in psychiatric places: 10 characteristic mental state features in patients with definite NMDAR-antibody encephalitis. J Neurol Neurosurg Psychiatry 90:A11-A12 